\title{
On political semiotics
}

\section{Andrey Makarychev ${ }^{1}$}

Review of Introducing Relational Political Analysis: Political Semiotics as a Theory and Method [Palgrave Studies in Relational Sociology] by Peeter Selg and Andreas Ventsel. Cham: Palgrave Macmillan, 2020, 319 pp.

In recent years there have been several attempts to bridge the interdisciplinary gaps between semiotics and political studies, two distinct research fields that synergetically gravitate towards each other. The book authored by Estonian scholars Peeter Selg and Andreas Ventsel seems to be one of the most fruitful theoretical contributions to the growing realm of political semiotics. In this review I will look at this volume from a political science and international relations perspective, trying to find out how exactly semiotic analysis may foster a better understanding of politics and its undercurrents.

On a general note, what scholars in domestic and foreign politics may borrow from this book is a useful distinction between self-, inter- and trans-actionalism. In a self-action framework, power is a type of property, and the sphere of politics is populated by pre-given agents operating according to their own powers of which they are primary sources; accordingly, voluntarism and determinism define the course of political process. Inter-actionalism can be perceived through the realist metaphor of "billiard balls" and the ensuing presumption of a stable and fixed agency, which by the same token implies communication, presumably both cooperative and conflictual. As seen through the trans-actional lens, politics is shaped by reciprocity, the mutable character of roles and identities, and their interdependence; in this logic, power cannot be located and may derive from anything (Selg, Ventsel 2020:31-32). This triad is instrumental for distinguishing between different conceptualizations of power - as an introverted and allegedly self-sufficient phenomenon, as an interest-based system of various interactions, and as a normative, networked and dispersed form of hegemony. This categorization appears to reach beyond the widely spread dichotomies (liberal - illiberal,

1 Johan Skytte Institute of Political Studies, University of Tartu, Estonia; andrey.makarychev@ut.ee. 
democratic - autocratic, left - right) and unpack different logics and philosophies of power relations.

Another nuanced assumption, grounded in the authors' semiotic reading of politics, concerns the level-of-analysis debate, yet in the meantime contains much more far-reaching conclusions. Selg and Ventsel venture to claim that the concept of democracy and its derivatives should be mostly applied to specific policies and actions, "whether they happen to be in a formally democratic or undemocratic regime [...]. [Therefore] there can be [...] extensive or regular democratic processes in a formally non-democratic country" (Selg, Ventsel 2020: 86). A similar argument strongly resonates in the field of critical geography and, in particular, in the works of Natalie Koch who argues, for instance, that instead of "authoritarian states" we should better speak of "authoritarian hands" of specific rulers and policy- and opinion-makers, and abstain from attributing authoritarian (or, presumably, democratic) characteristics to the entire polity or a country. To project this logic into the domain of international politics, it is expectable that major international actors committed to normative policies are likely to pursue "diffuse goals" (Koch 2019) aimed at supporting liberal practices and creating liberal spaces of education, governance, and culture in overwhelmingly illiberal environments. In this context, democracy ought to be seen "as a mode of being rather than a certain form of rule" (Selg, Ventsel 2020: 88), which can also be applicable to non-democracy, especially in its illiberal form.

This discussion might be extended onto the realm of populism studies, to which Selg and Ventsel contribute with a pertinent discussion on democratic, totalitarian and authoritarian forms of populism (Selg, Ventsel 2020: 179). What stems from this categorization is that populism has colonized the entire political spectrum and can take dissimilar ideological shapes. Consequently, populism is not a sort of political trademark belonging to specific actors as its "possession", but rather a series of contingent discursive articulations (Selg, Ventsel 2020: 180) sustained by an "emotive power" (Selg, Ventsel 2020: 204) - a concept that seems to be quite close to Judith Butler's theory of performativity. This approach to populism as a transgressive and performative phenomenon can be instrumental for comprehending the possibilities of transformations of democratic practices into a totalitarian populism (see, for example, Pine 2020), and multiple overlaps between them (Selg, Ventsel 2020: 203). The authors' discussion about "freedom (a liberal content) in a totalitarian form" (Selg, Ventsel 2020: 10) should be read exactly from this vantage point - as a reminder about always elusive, uncertain and blurred boundaries of freedom, and the possibility of its transmutation into a totalizing and unifying force. 
Against this background one may presume that Selg and Ventsel's relational political analysis is quite close to non-representational and non-foundational theorizing about politics. For example, they claim that for certain types of discourses and imageries "no relation between the signifier and the signified is necessary" (Selg, Ventsel 2020: 163), which attests to their inclination to look beyond the representational forms of meaning-making. In this vein, naming as a hegemonic operation (Selg, Ventsel 2020: 151) can also have far-reaching consequences for political analysis. Naming is a key element of what might be dubbed epistemic power that can re-signify concepts and ideas we use as parts of our political language, or can imaginatively create objects that "had never existed" (Selg, Ventsel 2020: 239). Both options can be discussed as important elements of the post-truth society, which is an effect of not only intentional production of lies and disinformation, but also of the crisis of representation and the proliferation of a post-foundational way of thinking about politics.

Highly expedient in this sense is the concept of "wicked problems" for which "there cannot be any experts or specialists in the strict sense, and often scientific and rigorous method-based approach to their solution can be futile" (Selg, Ventsel 2020: 57). Looking at this from the perspective of today's experience of the pandemic crisis management, the very existence of "wicked problems" appears to undermine Foucault's nexus of power and knowledge. The cognitive deficit easily observable during the Covid-19 lockdowns opens up at least two mutually exclusive perspectives. One can bring us towards the Schmittian political-willbased decisionism, legitimized by the top-down-imposed search for "friends" and "enemies". Another option, which seems to be more likely nowadays, is the reactualization of the Foucauldian responsibilization as a potentially effective mechanism of societal survival against the backdrop of the widely spread state of confusion and indecision in many governments tackling the coronavirus intrusion.

Within this context several references of the authors to a biopolitical vocabulary - such as "forms of life" (Selg, Ventsel 2020: 5), or the biopower-security nexus (Selg, Ventsel 2020: 52) - seem to have a strong potential for further developing the relational political analysis. The semiotic reading of biopolitics can go much beyond the corporeal and bodily characteristics of the "wicked problems". It is within the biopolitical theorizing of Giorgio Agamben that the frequent indistinction between democracy and its opposites can find its well-articulated interpretation. Populism, especially its right-wing forms, can be approached as a biopolitical construct (see Yatsyk 2020) with a strong semiotic content. In this regard, the diverse interconnections between cultural semiotics and biopolitics look like a promising academic project to explore in the future. 
532 Andrey Makarychev

\section{References}

Koch, Natalie 2019. Post-triumphalist geopolitics: Liberal selves, authoritarian others. ACME: An International Journal for Critical Geographies 18(4): 909-924.

Pine, Jason 2020. Populist realisms and counterfeit aesthetics. Culture Machine 19.

Selg, Peeter; Ventsel, Andreas 2020. Introducing Relational Political Analysis: Political Semiotics as a Theory and Method. Cham: Palgrave Macmillan. https://doi.org/10.1007/ 978-3-030-48780-5

Yatsyk, Alexandra 2020. Biopolitical populism in Poland: the case of PiS. Populism 3(2): 148-164. https://doi.org/10.1163/25888072-BJA10015 